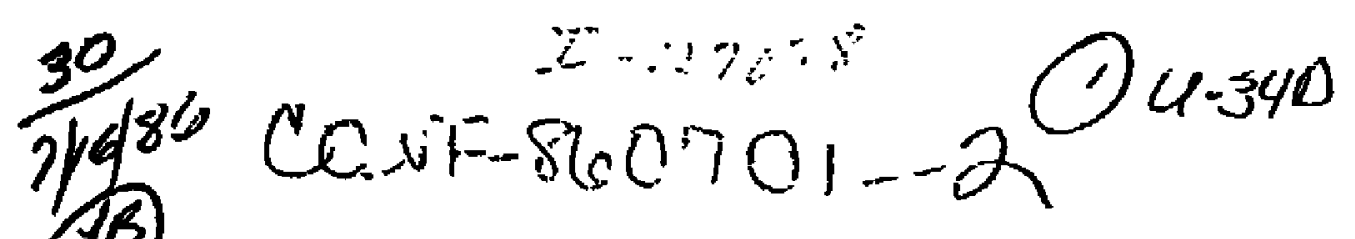

\title{
SUAC-PUB-4003
}

\section{DE86 012958}

Search for Single Photons from Radiative Neutrino or Euparymmetric Particle Production"

W. T. Ford, W, Q1, A. L. Read, Jr, and J. G. Smith Department of Physies, Univerrity of Colorado, Boulder, Colorado sosog and

T. Camporesi,jl. Perueti, and M. Piecolo

I. N. F, N., Loboratori Nasionali di Fraseati, Fraseati, Jtaly and

R. B. Kunt,iK. H. Ltu, J. Pyrlik, J. P. Venuti, H. B. Wald, and R. Weinstein Departiment of Phyries, Unvorrsity of Houston, Bouston, Texas 77004 and

B. R. Bund', M. W. Gettnor, G. P. Goderre, J. H. Moromisato,

W. D. Shambroom, (6) J. C. Sleeman, and E. von Goeler

Dopartment of Physies, Northeastern Universily, Boston, Massachusetts 02115 and

W. W. Anh, G. B. Chadwick, R, E. Leedy, R. L. Messner,

L. J.' Mone, F. Mulles, (b) H. N. Nelson, D. M. Ritson,

- L. J. Rounborg, D. E. Wirer, and R. W. Zdarko

Department of Physics and Slanford Linear Accelerator Center, Slanford Univaraity, Slanford, California 9/905
D. E, Groomind A, G. Verdini
Department of Phynies, Univeraity of Utah, Salt Lake City, Utah 84112 and
M. C. Dalfino,jJ, R. Johnon, T, L. Lavine, T. Maruyama, ard R. Prepost Department of thyeice, University of Wisconsin, ifostison, Wiseonsin 59706

Contributed to the XXIII Intermational Conference on High Energs Physics, Berkeley, Calliornia, July 26-23, 2986

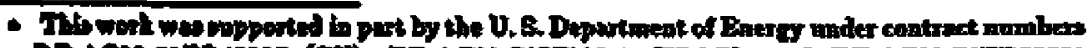

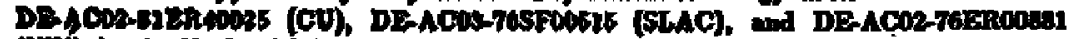

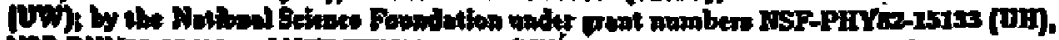

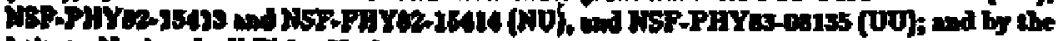

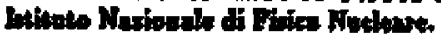




\title{
DR 1819.8
}
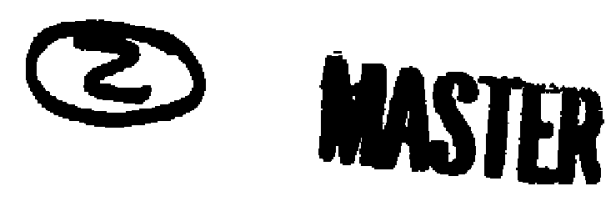

\begin{abstract}

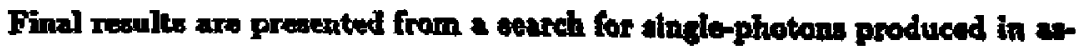
sociation with noutrinos or other weakly latatuctine neutral purticles in eteannihilations at $\sqrt{5}=29 \mathrm{GeV}$. The search we performed with the MAO dotector at PEP in totel integrated luminosity of $177 \mathrm{pb}^{-1}$. The search limite the number of light-neutrino fumilies to $N_{\nu}<16$. The mas of the sulectron is limited to $m_{i}>50 \mathrm{GeV} / c^{2}$ if $m_{i_{i}}=m_{i_{k}}$ and $m_{i}=0$. The mane of the wino is limited to $m_{\tilde{W}}>51 \mathrm{GcV} / c^{2}$ if $m_{\theta}=0$. These limile are at the $\infty 0 \%$ confdence level.
\end{abstract}

\section{DISCLAIMER}

This report was prepased as an account of wotk sponsored by an agency of the Unlted Sinten Governmem. Neither the United States Government nor any agenoy therews, nos any of thelf cmployces, mukes iny warranty, express of impiied, or assumes any legal liablity or rexponsibility for the accuracy. compleieness, or usefulness of any informatlon, apparatu, product, or process disclosed, or sepresents that its was would not infringe privately owned rights. Reforence herein to any specific commercial product, process, or sorvleo by trade sama, trademark, manufacturer, or otherwise does not necessarily constliute or imply lte endorstment, recommendation, or fayoring by the United States Government of any agency thereof. The viewn and epintons of authurs expressed herein do not thectssarily state of reflect those of the United Slotes Gowernment or any agenty theteof. 
Searche for photona from the reaction $e^{+} e^{-} \rightarrow$ Fĩ mont rentrietive limits on the masses of possible supersymmetric partners to the electron $(\hat{c})$ and photon $(\tilde{\gamma})$ in models where the the $\bar{\gamma}$ is light and stable. ${ }^{1,2} A$ dominunt buckpround to these seanches, the reaction $e^{+} e^{-} \rightarrow \nu F \gamma$, is also of considerable interest since part of the crosas section is sensitive to $N_{\nu}$, the number of light-neutrino familiew." Present limits on $N_{y}$ from $e^{+} e^{-}$, although not quite as retrietive as recent pp collider results, ${ }^{4}$ provide en independent messurement of this fundementw quantity. This paper reports final results from a search for single-photons accompanied by weakly interactirs particles in three data samplea totalling $177 \mathrm{pb}^{-1}$ of $e^{+} e^{-}$interactions accumulated by the MAC detector on the PEP storage ring at SLAC. An improved underntending of beam-related beckgounds is incorporated in a meximum likelihood analysis allowing an improvement in the limtts on radintive neutrino and photino production compared with previous publicetions of this search. ${ }^{1}$ New limits on radiative sneutrino production from the calculation of Grifols, Martinez, and Sold ${ }^{5}$ are presented.

Although supersymmetric (SUSY) theories continue to generate much theoretical activity, none of the predicted partners to ordinary particles has yet been found. in many SUSY models the lightest SUSY particle is neutral, stable, inleracts only weakly with matter, and thus cannot be directly detected. Two eandidates for thin lighteat SUSY particle which can be produced in $e^{+} e^{-}$inter-

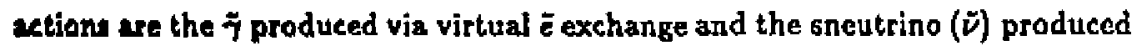
via $Z$ or supersymmetric $W(\widetilde{W})$ exchange. The cross section for radiative produetion of $\bar{\gamma}$ or $\bar{\nu}$ pairs is a function of both the $\bar{\gamma}$ or $\bar{\nu}$ masses and the masses of

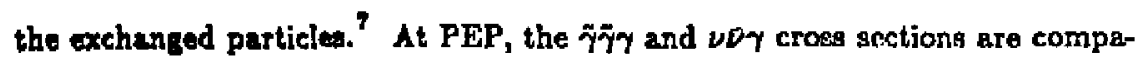


rable for $m_{i_{L}}=m_{\overline{i n}_{n}}=50 \mathrm{GeV} / \mathrm{c}^{2}, m_{\bar{i}}=0$, and $N_{\nu}=3$. The $\overline{\bar{y}} \overline{\bar{y}} \mathrm{y}$ cross section for $m_{\tilde{W}}=50 \mathrm{GeV} / c^{2}$ and $m_{\tilde{\nu}}=0$ is twice large.

Photons from $e^{+} e^{-} \rightarrow \nu \bar{\nu} \gamma_{,} \bar{\gamma} \bar{\gamma} \gamma$, and $\bar{\nu} \bar{\nu} \gamma$ have similar energy and angular distributions, peaked sharply at low energy and at amall poler angles. Other radiative processes, $e^{+} e^{-} \rightarrow e^{+} e^{-} \gamma, \gamma \gamma \gamma, \mu^{+} \mu^{-} \gamma$, and $\gamma^{+} \tau^{-} \gamma$, can also produce single-photon events if the other particles in the event are lost into uninstrumented or inefficient regions of the detector. For a detector completely effeient above some polar angle relative to the beam axis, the background from $e^{+} e^{-\gamma_{1}}$ $\gamma \gamma \gamma$, and $\mu^{+} \mu^{-} \gamma$ is kinematically limited to $E_{\perp \gamma} \leq\left(\sqrt{5}-E_{\gamma}\right)$ sin $\theta_{\text {voto }}$ where $E_{\perp \gamma}$ is the transverse energy of the detected photon und $\theta_{\text {vato }}$ in the muximum polar angle of undetected particles. This restriction does not apply to $t^{+} e^{-} \rightarrow r^{+} r^{-} \gamma$ where decay neutrinos may carry significant momentum. However, given the photon energy resolution, the luminosity, and $\theta_{\text {vetor }}$ the background from all of these processes is easily calculated. The dato in this report were collected in threc running periods of differing $\theta_{\text {veto. The single-photon search region for each }}$ period was chosen accordingly.

The MAC detector, composed of calorimetric and tracking chamhers covering $>98 \%$ of $4 \pi \mathrm{Br}$, has been deacribed in previous reports." Of particular importance to this experiment are the electromagnetic shower calorimeters (SC) in which photon energies and directions are measured, and the endcap calorimeters (EC) and small angle detectors which define $\theta_{\text {veto. }}$. The other MAC detector elements (inner and outer drift chambers, hadron calorimeters, and scintillation counters) provide rejection of cosmic ray, single-electron, and besm-related backgrounds. The 14 radiation length (t.l.) SC, constructed from alternating rianes of lead 
and proportional wios chabur (PWC) covering $35^{\circ}<0<145^{\circ}$, is argmeded

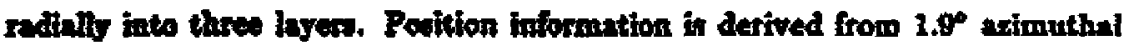
segments difitived at both andy. The angular resolution has been determined from radiative Bhuble senttaring evente to be $1.3^{\circ}$ in aximuth $(\phi)$ and $1.7^{\circ}$ in the polar angle (O). The enerd recolution is $\sigma_{S} / B=20 \% / \sqrt{E(\mathrm{GeV})}$.

The first dats oumple of $36 \mathrm{pb}^{-1}$ was collected with the original detector configuration. Sndeap eajorimeters covered poler angles greater than $10^{\circ}$ with at lent 20 r.l. of tebl and PWO planes. A siagle plane of scintillators provided redundant coverage to about $12^{\circ}$ from the bem axis. Fully efficient small angle veto enlorimetert $\left(\mathrm{SAV}\right.$ ) covering $3.8^{\circ}<0<17.5^{\circ}$ were instulled for the second date ample of $80 \mathrm{pb}^{-1}$. Downstream of the $\mathrm{SAV}$ detector, smsll angle tagging counters (SAT) covor BB\% of the simuth between $2.5^{\circ}<\theta<6.2^{\circ}$. Each SAV was constructed from alternating dincu of lead and PWC planes totalling 8.5 5.l. Euch SAT was made fron 6-8 s.l. of lead backed by $2 \mathrm{~cm}$ of plastic scintillator. Mechenical supports for tho beam pipe precluded complete szimuthal coverage for the BAT. A vertox chumbar (VC) was installed for the last data sample of $61 \mathrm{pb}^{-1}$. The additional shlaldins necosary for the VC obstructed the SAV and SAT below 6.8 . Rlng of 24 btamuth garmanate (BGO) aryatals with photodiode readout wore added between the $V O$ and ahielding, recovering part of the lost veto covarage. Thes BGO ring cover $4.9^{\circ}<0<7.2^{\circ}$ with 10 r.l. of active materiel.

Dete for this experimen , ware collected with a tinglephoton trigger requiring energy deposition in at kat two of the gC tyest and a minimom of 1 GeV of

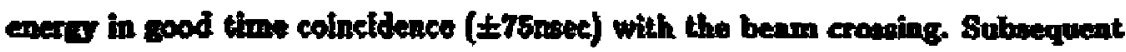


date analyois required that candidate events have a photon well imoide the SC, $40^{\circ}<\theta_{7}<140^{\circ}$, and that no evidence of other particter appenr in any of the other parts of the detector. Cuts applied on the e-.urg depoeition pattern ware designed to reject cosmic ray, beam-relnted, and noise backgrounda. A detailed description of the event aelection followa.

Photon showers were recognized by a clustering algorithm that combined calorimeter hits above $100 \mathrm{MeV}$ from the SC, EC, and hadron calorimeters with neighboring hit in $\phi$ and $\theta$. The mininum cluster containe two hits. Clunters were allowed to span calorimeter boundarien and wore allowed to extend into the hadron calorineter. Each shower was aulgned aner $\bar{E}$ and angle $\theta$ ard $\phi$ from the scalar and veetor sum of its individual hith. Osly ovents with a single cluster greater than $10^{\circ}$ from the beam exis wore kept. Ironh inlitated by showering charged particlea were reduced by zejecting evente with more than four central drift chamber hits. Events with on outer drift chambar trecle of with greater than $30 \%$ of the cluster energy in the hadron calorimetar wore Identibed a conmie rays and rejected. Cuts on smull angle detectors fnutulled after the irat date period were made to reduce Avato to angles below the endeape. Bventa were vetoed if the energy in the SAV was groutor than 280 MVV. For the socond data anpile, events were sloo rejected if the SAT was hit. The 8AT wa not uned in the third data sample. Intead, events with preater than $100 \mathrm{MoV}$ in the BCO rings were rejected.

Events surviving the above cuts inchuded $e^{+} e^{-} \rightarrow t^{+} t^{-} \gamma$ and 77 , back

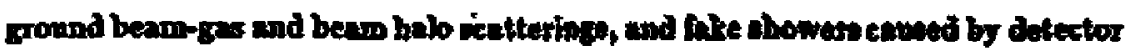
naise To further reduce the backgrownde, cuto were made on the thower profile. 


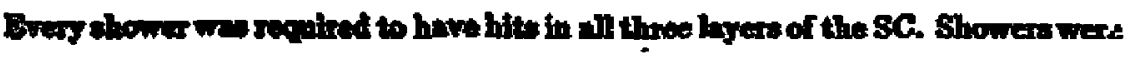

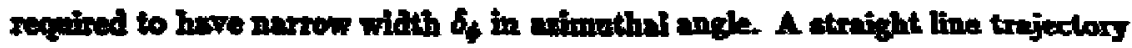
not ecoutrained to the bain viatex was ft to the bits in each shower. The point of intermetion to with the beam axis in the plane containing the beam axis and the whower centroid, und it diftance of cloceat approuch $r_{\min }$ to the inieraction point in the plene tranoverse to the beam axis, were calculated with a resolution $\sigma_{m}=12 \mathrm{~cm}$ and $\sigma_{\mathrm{r}=\mathrm{w}}=3.3 \mathrm{~cm}$. Shonen were required to have $r_{\min }<15 \mathrm{~cm}$. Eventu puening thewe cutu are identibied a vinglephoton candidates.

In previous andyne of this search, cendidatio with $|20|<30 \mathrm{~cm}$ and narrow thower wdth of in poler angle ware anumed to be a background-free selection of aluglophotone tinee showers with these proparties are consistent with photons produced at the e $e^{-}$- mtercetion polnt. The $E_{17}$ distributions of these singlephoton are ahown in Fis, 1 for the three date anmples. In this asalysis, the candidatem reloctad without euta on and $\delta$ are expectod to include events from basm-gas and beam halo beckgrounds. A maximum llkelihood analysis is employed to eatlmate the oive of the true aingle-photon signal in the presence of beam-salutad bukground, Flut, 2 senrch ragion with limited contamination from QED buekgrounde is dotermined.

The efilelency of the cuts and triager were determined with showers from rediative Bhabha weattering eventa. Lowee due to buckground noise in the SAV, SAT, BGO, drift, ealorimeter and weintillator detectore were tudied with beam crosing ealected at random. The photon conversion probability in the beam pipe wa 2-5\% depending on the running period. The overall efficiency for each data napule, caleulated from the produet of the above efficiencies, typically rlses 


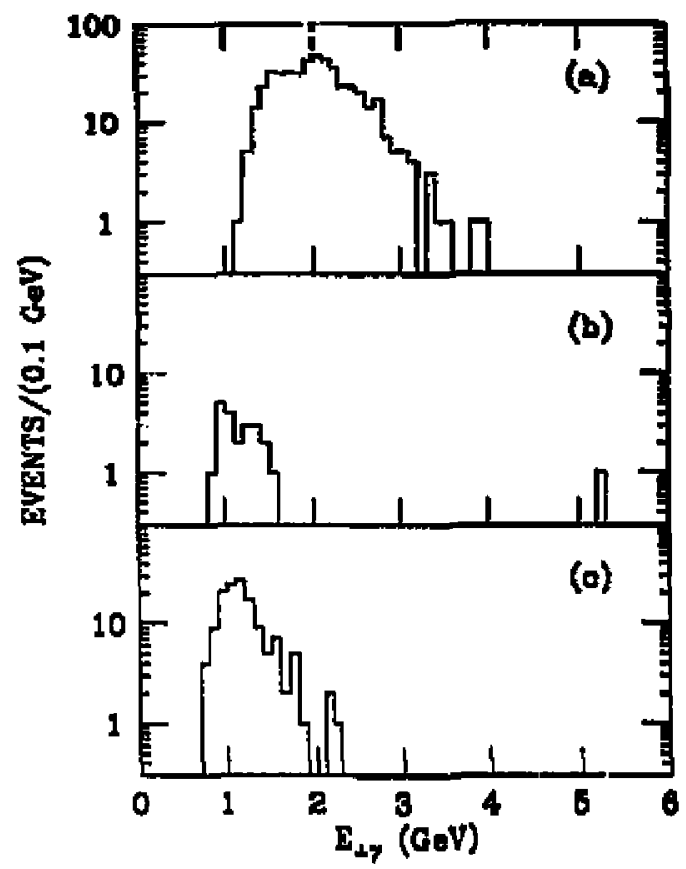

FIGURE 1. $E_{\perp \gamma}$ spectrum of single-photona $\ln (\mathbf{a})$ the firat data anmple of $36 \mathrm{pb}^{-1}$ with $\theta_{\text {voto }}=10^{\circ}$ and search region $E_{\perp y}>4.5 \mathrm{GeV}$, (b) the second data sample of $80 \mathrm{pb}^{-1}$ with $\theta_{\text {vato }}=2.6^{\circ}$ und weareh roglon $E_{\perp 7}>$ $2.0 \mathrm{GeV}$, and (c) the third data asmple of $61 \mathrm{pb}^{-1}$ with $\theta_{\text {vate }}=4.5^{\circ}$ and search region $E_{\perp \gamma}>2.6 \mathrm{GeV}$.

from $53 \%$ at $E_{\perp_{7}}=2.0 \mathrm{GeV}$ to $69 \%$ at $E_{17}=4.5 \mathrm{GaV}$.

The QED background was calculated by Monto Carlo simulation. The singlephoton $E_{\perp \gamma}$ spectra of simulated $e^{+} e^{-} \gamma, \gamma \gamma \gamma, \mu^{+} \mu^{-} \gamma$, and $\gamma^{+} \gamma^{-} \gamma$ events ${ }^{*}$ cotrected for resojution, acceptance, efficioncy, and luminonity was determined for different $\theta_{\text {reto. }}$. The beat $\theta_{\text {voto }}$ fit to each data tample agreed with the angles expected from the geometry of the small anglo deteclora. A soparate analyila 


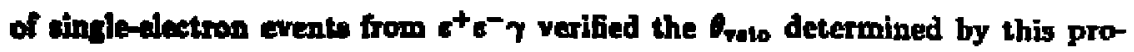
cedure $A$ earch rejoin for each of the threa running periods wat defined such that the combined background from $e^{+} e^{-} \gamma, \gamma \gamma \gamma_{1} \mu^{+} \mu^{-} \gamma_{1}$ and $r^{+} \gamma^{-} \tau$ events was expected to be lese than 0.1 event in each search region. The search regions are (a) $E_{\perp 7}>4.5 \mathrm{GeV}$, (b) $E_{\perp 7}>2.0 \mathrm{GeV}$, and (c) $E_{\perp \gamma}>2.6 \mathrm{GeV}$. The expected jield of photons from $e^{+} e^{-} \rightarrow N_{7}\left(N_{\nu}=3\right)$ is 0.1 in (a), 0.6 in (b) and 0.4 in (c). There are 10 singls $z^{-h}$ nton candidates in the search region, all from the second rtuning period.

Uallke the above QED procesgen, it it diffeull to make sn accurate estipante of the sive of possible buckgrounds from beam-gas and beam halo interaction. Sinee the general characteristics of showers produced by beam-related backgrounds difer from showers initiated by photons produced at the $e^{+} e^{-}$colItaion point, a maximum likelihood analysis can be used to estimate the true tise of the ainglo-photon vignal in the presence of this type of background. The broad distribution of beam-related backgrounds along the buan axis and the shellow trajectories at which background particles entor the detector give background ahowern a broader distribution of reconatructed axial vertex positions $z_{0}$ and shower wldthe 40 than ahowers from photons which originate from the $e^{+} e^{-}$ collision point. The messured $E_{\perp}$ apectrum of these backgroutnds falls off more steeply thun for signal.

Diatributions of measured $z_{0}, \delta_{0}$, and $E_{\perp}$ for the beam-related background are determined with a backeround sample containing 67 events that have measured $E_{\perp}$ in the tinglo-photon vearch region but fail the cut on the maximum allowed at-:ber of central drift chamber hits. The drift chamber hits in the events in 
the background sample were caused predominantly by charged partieles that entered the detector from one end and traversed aoveral layera of drift cells before showering in the SC. Distributions of 20 and $\delta$ for aignal evente are mearured with showers from radiative Bhabha seatterint ovents. The distribution of $\mathrm{E}_{\perp 7}$ for signal is chosen to be the differential tross section tor $e^{+} e^{-} \rightarrow q \nu$, which is similar to $e^{t} e^{-} \rightarrow \gamma \bar{\gamma} \bar{\gamma}$ for $m_{\bar{q}}=50 \mathrm{GoV} / c^{2}$ and $m_{\bar{q}}=0$.

The probability of finding $n$ events, from signal and $b$ from beam-related backgrounds, with measurements $x_{0 i}, \delta_{d i}$, and $E_{1 i}$ for $i=1, \ldots, n$, in the generalized likelihood function ${ }^{10}$

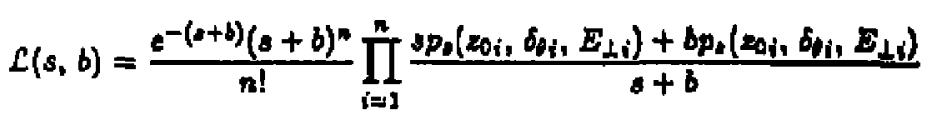

where $p_{s}\left(z_{0 i}, \delta_{\theta_{i}}, E_{\perp i}\right)$ and $p_{s}\left(z_{0 i}, \delta_{9 i}, E_{\perp i}\right)$ are the probabilities for making the observed measurements on signal and background events, respectively. The maximum likelihood estimate of the number of signal events in the seareh region is the value $s=\hat{s}$ which maximizes $\mathcal{L}$ for the $n=10$ single-photon candlates. The maximum likelihood estimate of signal from equation ( 1 ) is $s=0.99$ events, which agrees with the previous analysis of this search in which cuta on $z_{0}$ and $\sigma_{8}$ retained one event in the search regions. ${ }^{3}$ The confidence level of an upper linit $S$ on $s$ is computed by a Monte Carlo method at the fraction of equivalent experiments that, when exposed to a true number of signal avents $S$, would estimate a number of signal events larger than the $\mathbf{b}$ estimated in this experiment. The 90\% confidence level upper limit on signal is $S=3 . t$ events. Estimates of the systematic error in $S$ due to determining the background distributions from the 67 event background ample lead to upper limitu no more than 0.05 events 
larger than the above $S=3.7$. The rendte of the maximum likelihood analysix ane insensitive to whather or wol the amn QDD beckground to the soarch re-

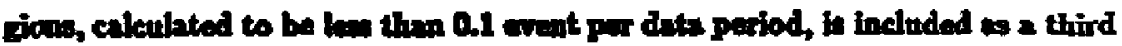
parameter in the llikellibod funation.

The 37 event upper linit on signal th the search regions correoponds to a Imit of $N_{0}<16$ at the $00 \%$ confidence level with no SUSY or backgromd prodration aseumed or aubleacted. Limits on anornalows stinde-pholon production

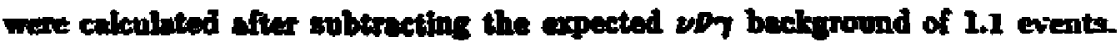

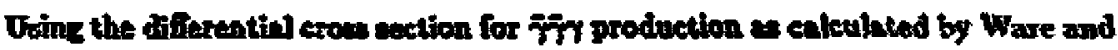
Machacex, ${ }^{32}$ the regions of excluded 8 and 7 manes are shown in Fit. 2 for (A) $m_{i_{2}}=m_{k_{1}}$ and (b) $m_{i_{2}}>m_{k_{k}}$, For $m_{4}=0$ the $00 \%$ eonfidence lovel limits on

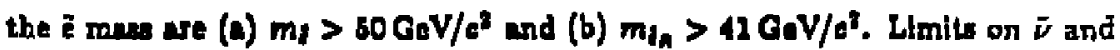
$\widetilde{W}$ manes depend on the specifc SUSY model solected. Ualng the ditierential cross sectlon for Dö̆ production a caleulated by Grifola, Martinez, and Solä, the regions of excluded $\widetilde{W}$ and $v$ masue we shown in Fig. 3 . For $m_{j}=0$ the $90 \%$ confidence level limit on the $\tilde{W}$ mue in $m_{\tilde{W}}>51 \mathrm{GoV} / \mathrm{o}^{2}$. These limits are higher then thote obtained In previous publlentions of thlo nourch ${ }^{1}$ and greater flowir or comparable to result from other sourchos. ${ }^{2}$

We thank J. D. Waxo and M. Martfoce for providing calculations of the $\bar{\gamma} \bar{\gamma}$ / and Ëj crosesections for the MAC detector aceeptance. Wo abo thanl N. Erickon, J. Becalera, M. J. Frankomili, and J. Sehroeder for tochnieal assistance. and the SLAC otar for contimned rellable operation of the PEP atorage xing. We

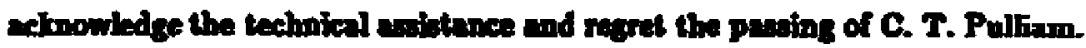




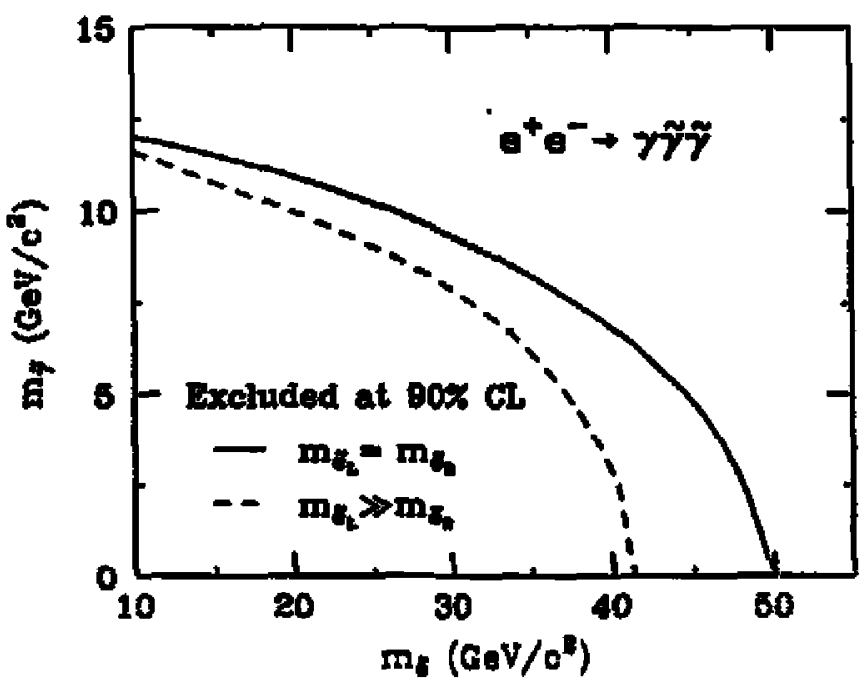

Figune 2. Lower llonitu on the 1 and mure determined by this experiment.

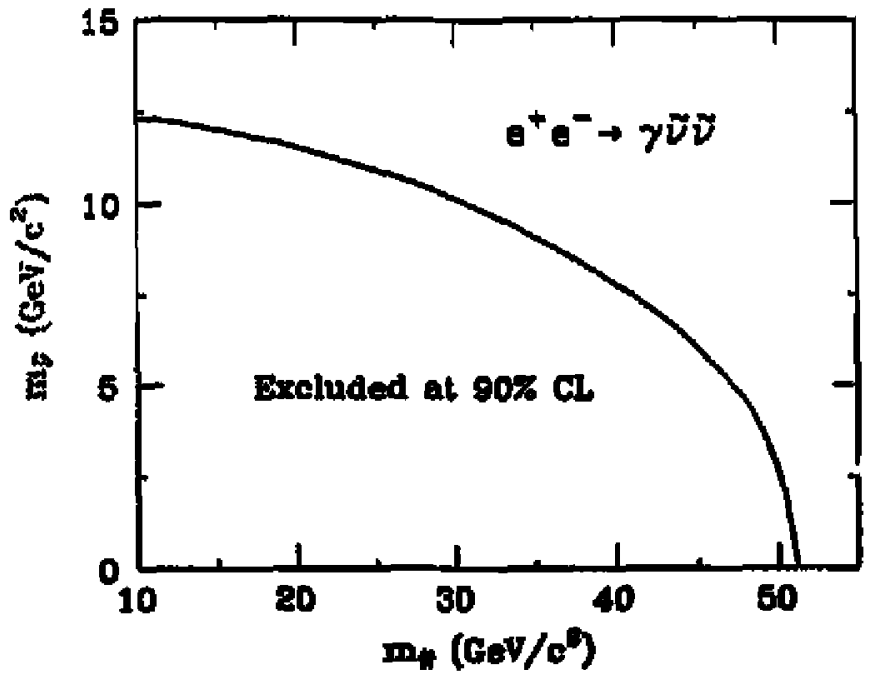

Fievas s. Lower fintte on the $\bar{W}$ and 5 manes determined by thin experiment. 


\section{REPEREHODS}

(a) Joint appolntment: Depurtment of Physics and College of Computer science, Northeastern University, Borton, Massachusetts 0211 .

(b) Permanent addrane CGRN, Ganeqs, Switzerland.

1. W. T. Ford at at. (MAC Collaboration), Phys. Rev. 880,347 (1986);

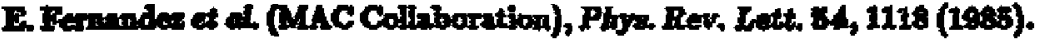

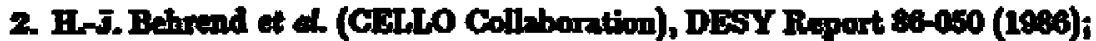

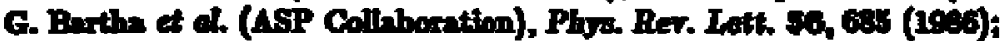

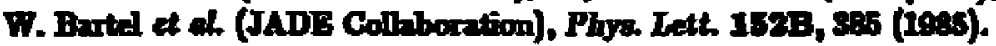

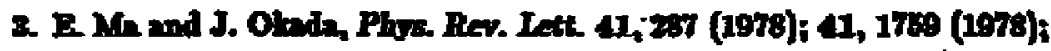

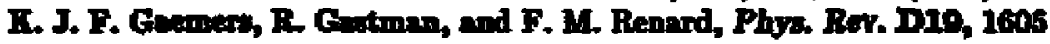
(19a).

4. G. Amion at af. (UA1 Colhabaration), Phys. Lett 168B, 484 (1986).

5. J. A. Grifols, M. Martize, and J. Boli, Nucl. Phys, Bnes, 151 (1088).

6. A recent and comprehensive review with references to the origind litaratura L H. E. Haber and G. L. Kane, Physics Reports 117, 76 (1985).

7. J. A. Grifoln, X. Mor-Mur, and J. Golà, Phys. Lett. 114B, 35 (1982); P. Fayet, Phys, Lott. 117B, 460 (1982);

J. E.llis and J. 8. Fucelin, Phys. Lett. 122B, 303 (1983);

3. 5. Fagdin, G. L. Kane, and 8. Daby, Nucl. Phys. B241, 688 (1984).

8. W. T. Ford, "The MAC Clorimeters and Applications," in Pme. Int Conf.

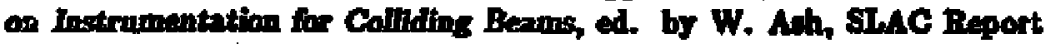
Ko. 250, p. 174 (19:2)

9. F. A. Bewads and R. Flan, Nuch Phym Beps, 537 (1983);

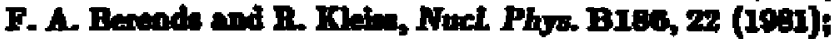

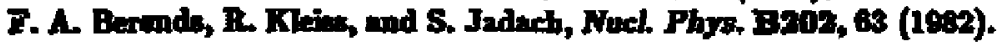

10. A. G. Froderen, O. Skjeggestad, and H. Thte, Probsbilty and Statistics in Particle Physies, Bergen, Norway, Univerbitetsforlaget, 1979;

L. Lyons and W. Allinon, Oxford University Nuclear Phyoles Laboratory Report (Print-85-0476), 1985.

11. J. Ware and M. D. Machacek, Phys. Lett. 142B, 300 (1984);

T. Kobayanh and M. Kuroda, Phys. Letl. 130B, 208 (1984);

K. Grasisie and P. N. Pandita, Phys. Rev. Da0, 22 (1904). 